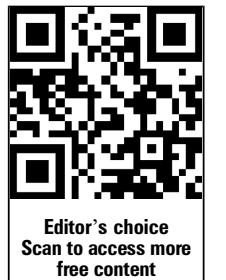

free content

Department of Public Health Sciences, Division of Global Health/IHCAR, Karolinska Institutet, Stockholm, Sweden

\section{Correspondence to} Dr Mathilde Sengoelge, Department of Public Health Sciences, Division of Global Health/IHCAR, Karolinska Institutet, Nobels väg 9 , Stockholm SE 171 77, Sweden; mathilde.sengoelge@ki.se

Received 4 September 2012 Revised 29 December 2012 Accepted 10 January 2013 Published Online First 12 February 2013

\title{
Country-level economic disparity and child mortality related to housing and injuries: a study in $\mathbf{2 6}$ European countries
}

\author{
Mathilde Sengoelge, Berty Elling, Lucie Laflamme, Marie Hasselberg
}

ABSTRACT

Objective Adverse living standards are associated with poorer child health and safety. This study investigates whether adverse housing and neighbourhood conditions contribute to explain country-level associations between a country's economic level and income inequality and child mortality, specifically injury mortality.

Design Ecological, cross-sectional study.

Setting/subjects Twenty-six European countries were grouped according to two country-level economic measures from Eurostat: gross domestic product (GDP) and income inequality. Adverse country-level housing and neighbourhood conditions were assessed using data from the 2006 European Union Income Social Inclusion and Living Conditions Database $(n=203000)$.

Main outcome measure Child mortality incidence rates were derived for children aged 1-14 years for all causes, all injuries, road traffic injuries and unintentional injuries excluding road traffic. Linear regression analysis was applied to measure whether housing or neighbourhood conditions have a significant association with child mortality and whether a strain modified the association between GDP/income inequality and mortality.

Results Country-level income inequality and GDP demonstrated a significant association with child mortality for all outcomes. A significant association was also found between housing strain and all child mortality outcomes, but not for neighbourhood strain. Housing strain partially modified the relationship between income inequality and GDP and all child mortality outcomes, with the exception of income inequality and road traffic injury mortality showing full mediation by housing strain. Conclusions Adverse housing conditions are a likely pathway in the country-level association between income inequality and economic GDP and child injury mortality.

\section{INTRODUCTION}

Systematic and broad socioeconomic inequalities exist in child mortality and morbidity rates throughout Europe, ${ }^{1-3}$ particularly in child injury, which is also the leading cause of mortality for children in Europe. ${ }^{45}$ Tackling the mechanisms of child health inequalities can significantly help to improve not only child health but also the life course. ${ }^{6}$ Thus, measuring differences in child mortality rates across Europe, specifically injury mortality, is important in order to reduce the cross-national gaps in child health and safety in the region. Social conditions are acknowledged as a fundamental cause of health inequalities ${ }^{7}$ and are relevant for child injury, as abundant research at the individual and area level proves that low socioeconomic status is detrimental to child safety. ${ }^{4} 58$ Two broad mechanisms at the individual level exist to explain this, namely, differential vulnerability and differential exposure. ${ }^{9-11}$ Child injury prevention has focused on differential exposure by targeting risks in and around the home environment. ${ }^{12}$ Adverse housing and neighbourhood conditions contribute to increased child injuries, as well as a range of other adverse health outcomes, ${ }^{13-17}$ and improving the housing conditions of vulnerable populations has the potential to improve health. ${ }^{18} 19$

Mechanisms also operate at the country level to explain the differences between countries in health disparities. These include national differences in social investment ${ }^{20} 21$ and levels of social cohesion, ${ }^{22}$ whereby countries with high economic inequality tend to show higher health disparity. ${ }^{23} 24$ In turn, lower levels of economic inequality and redistributive social health policies, those that provide more equal access to resources, are able to weaken certain aspects of the socioeconomic health gradient. $^{23-25}$ There exists a body of research investigating the unequal distribution of health linked to economic differences, ${ }^{10} 202627$ but injury has not received much attention. Yet, child injury rates have been shown to be strongly and positively associated with both country-level income inequality and adverse living standards. ${ }^{28}$ In this study, we investigate how housing and neighbourhood at the country level contribute to explain the association between economic differences and child mortality, specifically injury mortality.

\section{MATERIALS AND METHODS}

\section{Data source}

Country-level data from 26 European countries (Austria, Belgium, Cyprus, Czech Republic, Denmark, Estonia, Finland, France, Germany, Greece, Hungary, Ireland, Iceland, Italy, Latvia, Lithuania, Luxembourg, The Netherlands, Norway (special status country), Poland, Portugal, Slovakia, Slovenia, Spain, Sweden and UK) were derived from several sources, including the WHO Mortality Database (WHOSIS, http://www. who.int/whosis/mort/download/en/index.html), the European Statistical Office Eurostat and the European Union Income, Social Inclusion and Living Conditions Database (EU SILC), a multi-purpose instrument to provide comparative statistics on income distribution, living conditions and social exclusion (http://epp. eurostat.ec.europa.eu/portal/page/portal/income_social _inclusion_living_conditions/introduction).

\section{Outcome variable}

The outcome variable explored in this analysis was age-standardised mortality rates of children 
Table 1 Pattern matrix from the factor analysis with factor loadings significant at $(>0.50)$

\begin{tabular}{lll}
\hline $\begin{array}{l}\text { Housing/neighbourhood } \\
\text { conditions }\end{array}$ & $\begin{array}{l}\text { Factor 1: } \\
\text { housing } \\
\text { strain }\end{array}$ & $\begin{array}{l}\text { Factor 2: } \\
\text { neighbourhood } \\
\text { strain }\end{array}$ \\
\hline $\begin{array}{l}\text { Inability to keep home adequately } \\
\text { warm }\end{array}$ & 0.628 & 0.000 \\
$\begin{array}{l}\text { Leaking roof, damp walls/floors/ } \\
\text { foundation or rot in window frames } \\
\text { or floor }\end{array}$ & 0.533 & 0.187 \\
$\begin{array}{l}\text { Ability to make ends meet } \\
\text { Capacity to face unexpected financial } \\
\text { expenses }\end{array}$ & 0.767 & 0.638 \\
$\begin{array}{l}\text { Noise from neighbours or from the } \\
\text { street }\end{array}$ & 0.080 & 0.025 \\
$\begin{array}{l}\text { Pollution, grime or other } \\
\text { environmental problems } \\
\text { Crime, violence or vandalism in the } \\
\text { area }\end{array}$ & 0.094 & 0.767 \\
$\begin{array}{l}\text { Total disposable household income } \\
\begin{array}{l}\text { Total housing cost } \\
\hline\end{array}\end{array}$ & 0.345 & 0.779 \\
\hline
\end{tabular}

aged 1-14 years. The rates were calculated per country for all causes, all injuries combined, road traffic injuries and unintentional injuries excluding road traffic.

\section{Independent variables}

The key predictor of interest was the proportion of European households at country level with adverse housing and neighbourhood conditions. As such a variable does not exist, it was necessary to create an index of adverse housing and neighbourhood conditions differentiating European countries. Forty household- and neighbourhood-level variables were extracted from the 2006 EU SILC survey for the 26 countries, yielding a total sample size of approximately 203000 households based on country representative samples. We considered above all the variables with documented socioeconomic disparities within countries, for example, dwelling type, rental/owner status, leaking roof, pollution and crime around the home, as well as possession of material goods, such as a computer/television/ mobile phone, or capacity to face unexpected expenses. As high colinearity was expected between attributes, several of the 40 originally retained variables were eliminated on the grounds of redundancy (tested using Spearman's rank and Pearson coefficient correlations). The remaining housing and neighbourhood attributes that showed wide disparities between countries were then analysed by means of an exploratory factorial analysis using the principal axis method with oblique rotation. Factor scores were estimated by creating the linear composites of observed items, that is, the scores resulting from adding the optimally weighted scores of countries on the characteristics in question. ${ }^{29}$ The factor analysis based on the EU SILC variables generated two specific factors that were labelled housing strain and neighbourhood strain to reflect adverse housing and neighbourhood conditions (table 1). These two factors together explained $42 \%$ of the total variation in the data $(26 \%$ and $18 \%$, respectively).

Other covariates included in the analysis were two country-level economic indicators for the reference year 2006. Data on a country's gross domestic product (GDP), defined as millions of purchasing power standard, were derived from Eurostat (http://epp. eurostat.ec.europa.eu/statistics_explained) to represent economic differences between the countries. Income inequality used to reflect differences within countries was defined based on the Eurostat 80:20 income quintile share ratio, a ratio of the percentage of cumulative income held by the richest $20 \%$ and poorest 20\% population deciles (http://epp.eurostat.ec.europa.eu/ statistics_explained/index.php/Social_inclusion_statistics\#Income inequalities).

\section{Statistical analysis}

The housing and neighbourhood strains derived from the factor analysis were regarded as occupying an intermediate causal position between the economic measures and child mortality. Linear regression analysis was applied to measure if the housing and neighbourhood strains have a significant association with various causes of child mortality. Next, we tested whether a strain found to be significant modified the association between GDP/income inequality and child all-cause mortality and injury mortality. In order to satisfy the underlying assumption of linear regression, the GDP data underwent a log transformation to follow a symmetrical distribution. CIs were set at $95 \%$ and $p$ values at $<0.05$ (two-sided). Data analysis was performed using SAS software, V.9.2 (SAS Institute Inc., Cary, North Carolina, USA).

\section{RESULTS}

In our analyses, the regression showed a significant association between housing strain and all child mortality outcomes, but not for neighbourhood strain (table 2). The strongest association existed for all-cause child mortality, which increased by 10.66 (95\% CI 4.62 to 16.69 ) deaths per 1000 children as housing strain increased. The weakest association, nonetheless, was still significant for road traffic injury mortality.

Table 3 shows a significant association between the two country-level economic measures, income inequality and GDP, and child mortality for all outcomes. The strongest association existed for all-cause child mortality, which increased by 2.93

Table 2 Association between housing strain and neighbourhood strain and child mortality

\begin{tabular}{|c|c|c|c|c|}
\hline & All cause* & All injury* & Road traffic injury* & Unintentional injury excluding road traffict \\
\hline \multicolumn{5}{|l|}{ Housing strain } \\
\hline Coefficient $(95 \% \mathrm{Cl})$ & 10.66 (4.62 to 16.69$)$ & 5.94 (1.58 to 10.30$)$ & 2.31 (0.98 to 3.64$)$ & 3.07 (0.15 to 5.98$)$ \\
\hline $\mathrm{p}$ Value & 0.001 & 0.010 & 0.002 & 0.040 \\
\hline \multicolumn{5}{|l|}{ Neighbourhood strain } \\
\hline Coefficient $(95 \% \mathrm{Cl})$ & $7.79(-4.26$ to 19.84$)$ & $5.67(-2.32$ to 13.67$)$ & $1.25(-1.43$ to 3.94$)$ & $3.98(-1.04$ to 9.00$)$ \\
\hline $\mathrm{p}$ Value & 0.195 & 0.156 & 0.346 & 0.115 \\
\hline
\end{tabular}


Table 3 Association between income inequality and gross domestic product (GDP) and child mortality modified by the housing strain

\begin{tabular}{|c|c|c|c|c|}
\hline & All cause* & All injury* & Road traffic injury* & $\begin{array}{l}\text { Unintentional injury excluding } \\
\text { road traffict }\end{array}$ \\
\hline \multicolumn{5}{|l|}{ Income inequality } \\
\hline Coefficient $(95 \% \mathrm{Cl})$ & 2.93 (1.42 to 4.45$)$ & 2.05 (1.07 to 3.03$)$ & $0.61(0.27$ to 0.95$)$ & 1.23 (0.58 to 1.88$)$ \\
\hline $\mathrm{p}$ Value & 0.001 & $<0.001$ & 0.001 & 0.001 \\
\hline \multicolumn{5}{|c|}{ Income inequality+housing strain } \\
\hline Coefficient $(95 \% \mathrm{Cl})$ & 1.97 (0.11 to 3.83$)$ & 1.77 (0.51 to 3.04$)$ & $0.39(-0.03$ to 0.81$)$ & 1.19 (0.34 to 2.03$)$ \\
\hline $\mathrm{p}$ Value & 0.038 & 0.008 & 0.069 & 0.008 \\
\hline \multicolumn{5}{|l|}{ GDP } \\
\hline Coefficient $(95 \% \mathrm{Cl})$ & $-10.66(-14.39$ to -6.92$)$ & $-6.55(-9.31$ to -3.80$)$ & $-2.50(-3.23$ to -1.77$)$ & $-3.40(-5.42$ to -1.38$)$ \\
\hline $\mathrm{p}$ Value & $<0.001$ & $<0.001$ & $<0.001$ & 0.002 \\
\hline \multicolumn{5}{|l|}{ GDP+housing strain } \\
\hline Coefficient $(95 \% \mathrm{Cl})$ & $-9.00(-13.75$ to -4.24$)$ & $-6.02(-9.61$ to -2.42$)$ & $-2.25(-3.20$ to -1.31$)$ & $-3.13(-1.77$ to -0.50$)$ \\
\hline $\mathrm{p}$ Value & 0.001 & 0.002 & $<0.001$ & 0.022 \\
\hline
\end{tabular}

${ }^{*}$ Mortality rate per 1000 children.

†Mortality rate per 10000 children.

(95\% CI 1.42 to 4.45 ) deaths per 1000 children as the ratio of country-level income inequality increased, and decreased by 10.66 (95\% CI -14.39 to -6.92 ) deaths per 1000 children as the GDP increased. Furthermore, housing strain partially modified the relationship between income inequality and all child mortality outcomes, except for road traffic injury mortality where the results support full mediation. When using GDP as the economic measure, housing strain partially modified the relationship between GDP and all child mortality outcomes.

\section{DISCUSSION}

\section{Main findings}

Our analyses show that in the European context statistically significant relationships exist between a country's GDP/income inequality and child mortality. Increasing GDP is significantly associated with a lower child mortality rate, from all causes and mortality from injuries, whereas the reverse holds that increasing income inequality is significantly associated with a higher child mortality rate. In addition, a significant association was found between housing strain and all child mortality outcomes, but not for neighbourhood strain. It may be that the variables available in the EU SILC survey representing the neighbourhood strain (crime, pollution, noise) were not specific enough to reflect child mortality outcomes. Further analysis found that housing strain partially mediated the association between income inequality or GDP and child mortality. The exception to this was income inequality and housing strain with regard to road traffic injury, in which housing strain fully mediated the association. One possible explanation is that children from poor families and from more deprived areas are more exposed to a wider range of hazards in the road environment. ${ }^{30}$

These data suggest that material deprivation in a child's environment, in the form of adverse housing conditions, negatively impact child mortality, as well as contribute to the effect of high income inequality or low GDP on child mortality. Other studies of this kind focused on high-income countries and therefore could not investigate whether housing conditions came into play for both economic level and income inequality. ${ }^{10}$ Due to the small sample sizes, the injury groupings did not allow for subtle variations to be observed, for example, between road user categories or between specific causes among unintentional injuries excluding road traffic.
A European quantification of the 'Environmental burden of disease associated with inadequate housing' showed that housing is a major public health issue costing lives. ${ }^{31}$ For example, the report estimated that a lack of window guards and functioning smoke detectors cause approximately 7500 injury deaths and over 200000 disability-adjusted life years in the European region annually. ${ }^{31}$ Research in the UK also showed that inadequate housing is a huge financial burden on the health sector, whereby investment on improving housing could save money and provide health benefits. ${ }^{32}$ Countries that have systematically addressed the social determinants of child injury also have the lowest injury mortality rates in the region. ${ }^{5}$ For example, Sweden's commitment to regulations and legislation mandating safer living environments, for example, window guards for homes, ${ }^{33}$ combined with a sense of social responsibility has resulted in decades of low child injury mortality rates. Furthermore, there is evidence showing that housing improvements addressing structural deficiencies (installed working smoke alarms, four-sided isolation pool fencing and preset hot water temperature) may assist in reducing unintentional deaths and injuries. ${ }^{34}$ This lends support to the notion that country differences in child injury may be influenced by unequal access to resources to ensure safe environments for children. Notably, this may operate even for high-income countries as shown in this study sample.

The study contributes to the body of research investigating more closely the potential macro-determinants of the unequal distribution of health. ${ }^{10}{ }^{28}$ The recent WHO report 'Environmental health inequalities in Europe' 35 confirms that environmental health inequalities exist in all subregions and in all countries of the European region, with each country having a specific portfolio of inequalities. These inequalities most often affect disadvantaged groups. As socioeconomic inequality is on the rise in numerous countries in Europe, such risk differentials must be addressed. ${ }^{5}$ This study is one of the first to measure the impact of country-level housing deprivation on child injury. It is essential to intervene as soon as possible in children's lives because longitudinal studies have revealed that multiple housing deprivation leads to a greater risk of disability or poor health in later life, ${ }^{36}$ independently of the effects of socioeconomic deprivation in child or adulthood. ${ }^{37}$

\section{Limitations}

This study covers a wide range of European countries and uses two different economic measures to explore the complex and 
difficult task of isolating the factors driving the association between economic disparity and child mortality at the country level. Although country-level comparisons are importantsometimes essential-for research and policy purposes, access to comparative material/data sources is seldom easy and often problematic. The EU SILC data used herein are collected by surveys, registers or a combination of both, and there is concern that this difference in sources may account for measured differences, especially as Nordic countries tend to use registers and also have lower levels of income inequality and relative poverty. ${ }^{38}$ Yet, it is recognised by Eurostat that there is a need for systematic assessment of EU SILC comparability with external sources. ${ }^{38}$ Furthermore, the data on housing conditions used to conceptualise the notion of the home environment indexes rely on self-reporting as no public health officials were employed to inspect the homes on site based on a standardised assessment form as is done in the UK. ${ }^{31}$ Thus, self-reporting bias may exist. Nonetheless, the EU SILC remains the key source for measures of income, housing, labour information and social exclusion due to its adherence to data quality guidelines and procedures aimed at maximising comparability at the EU level, as documented by Eurostat. ${ }^{38}$

Also, the conceptual limitation to the cross-sectional design is that it was only able to ascertain housing conditions that contributed to the association between two country-level economic differentials and child mortality. It is difficult to demonstrate measurable cause-effect relationships due to inadequate housing conditions often being linked with other forms of deprivation. ${ }^{12}{ }^{18}$ Finally, the association between country-level deprivation and all-cause/cause-specific mortality was analysed without being able to identify the independent contribution of the child and caregiver characteristics. It is extremely challenging for public health research to accomplish this on a European scale.

\section{Implications for prevention}

Reducing child health inequities in Europe is a matter of fairness and is economically necessary. The European Parliament estimates that losses linked to health inequalities cost around 1.4\% of the GDP within the European Union-a figure almost as high as the EU's defence spending at $1.6 \%$ of GDP. ${ }^{39}$ Yet, tackling these inequalities requires a public health shift from targeting individual risk factors to focusing on altering social conditions that affect health determinants. The Commission on Social Determinants of Health calls for improving daily living conditions as a primary goal for reducing health inequalities. ${ }^{4}$ As the health and well-being of children is a shared value among European countries, a multi-country approach is relevant and requires cross-sectoral commitment. The European policy to secure adequate housing conditions for all children in the region is a means to intervene in the complex social processes impacting child mortality. ${ }^{40}$ For prevention policy purposes, future research is needed to improve and standardise at the country level the cause and effect of housing and neighbourhood interventions linked to injury prevention efforts.

\section{CONCLUSION}

This study supports the notion that housing conditions operate at the country level by mediating the relationship between a country's economic-level GDP/income inequality and child mortality. Therefore, it is plausible that tackling housing conditions may buffer the association between a country's economic differentials and child mortality.

\section{What is already known on the subject}

- Injuries are the number one cause of death in children in Europe, have a strong socioeconomic gradient and are highly preventable.

- High income inequality and low economic level negatively affect child health and safety.

- Inadequate housing is associated with poorer child health and safety.

- Housing operates both at individual and contextual levels.

\section{What this study adds}

- In the European context, a significant association was found between adverse housing conditions and all child mortality outcomes, but not for adverse neighbourhood conditions.

- Adverse housing conditions were found to partially mediate the association between income inequality or GDP and child mortality.

- Housing conditions may buffer the negative impact of a country's economic differentials on child mortality.

Acknowledgements We thank David Ormandy for providing access to the EU SILC data and to Gabrielle Breugelmans for reviewing the manuscript.

Contributors All authors were involved in the study design. MS coordinated the data analysis and treatment and drafted the manuscript, including the presentation and interpretation of the results. BE analysed the data. All authors provided comments and edits on all subsequent drafts and approved the final manuscript.

Competing interests None.

Provenance and peer review Not commissioned; externally peer reviewed.

\section{REFERENCES}

1 European Commission. Reducing health inequalities in the European Union. Luxembourg: Publications Office of the European Union, 2010.

2 Mackenbach JP. Health inequalities: Europe in profile. London: Department of Health, 2006. http://ec.europa.eu/health/ph_determinants/socio_economics/ documents/ev_060302_rd06_en.pdf (accessed 10 Sep 2011).

3 Commission on Social Determinants of Health. Closing the gap in a generation: health equity through action on the social determinants of health. Geneva: World Health Organization, 2008.

4 Laflamme L, Hasselberg M, Burrows S. 20 Years of research on socioeconomic inequality and children's-unintentional injuries understanding the cause-specific evidence at hand. Int J Pediatr 2010;pii:819687.

5 Sethi D, Towner E, Vincenten J, et al. European report on child injury prevention. Rome: World Health Organization Regional Office for Europe, 2008.

6 Mielck A, Graham H, Bremberg S. Children, an important target group for the reduction of socioeconomic inequalities in health. In: Mackenbach J, Bakker M, eds. Reducing inequalities in health: a European perspective. London: Routledge, 2002.

7 Phelan JC, Link BG, Tehranifar P. Social conditions as fundamental causes of health inequalities: theory, evidence, and policy implications. J Health Soc Behav 2010;51: S28-40.

8 Peden M, Oyegbite K, Ozanne-Smith J, et al. World report on child injury prevention. Geneva: World Health Organization, 2008.

9 Blank N, Diderichsen F. Inequalities in health: the interaction between socio-economic and personal circumstances. Public Health 1996;110:157-62.

10 Wilkinson RG, Pickett KE. Income inequality and socioeconomic gradients in mortality. Am J Public Health 2008;98:699-704.

11 World Health Organization Regional Office for Europe. Socio-environmentally determined health inequities among children and adolescents. Copenhagen: WHO Regional Office for Europe, 2009

12 Kendrick D, Coupland C, Mulvaney C, et al. Home safety education and provision of safety equipment for injury prevention. Cochrane Database Syst Rev 2007;(1). Art. No.: CD005014. doi:10.1002/14651858.CD005014.pub2. 
13 Shaw M. Housing and public health. Annu Rev Public Health 2004;25:397-418

14 Shenassa ED, Stubbendick A, Brown MJ. Social disparities in housing and related pediatric injury: a multilevel study. Am J Public Health 2004;94:633-9.

15 Krieger J, Higgins DL. Housing and health: time again for public health action. Am J Public Health 2002:92:758-68.

16 Building Research Establishment. Good housing leads to good health: a toolkit for environmental health practitioners. London: Chartered Institute of Environmental Health, 2008.

17 Raymond J, Wheeler W, Brown MJ. Inadequate and unhealthy housing. Morb Mortal Wkly Rep 2011;60:21-7.

18 Thomson H, Petticrew M, Morrison D. Health effects of housing improvement: systematic review of intervention studies. BMJ 2001:323:187-90.

19 Gibson M, Petticrew M, Bambra C, et al. Housing and health inequalities: a synthesis of systematic reviews of interventions aimed at different pathways linking housing and health. Health Place 2011;17:175-84.

20 Commission on Social Determinants of Health. Towards a conceptual framework for analysis and action on the social determinants of health. Geneva: World Health Organization, 2005

21 Elstad J. Does the socioeconomic context explain both mortality and income inequality? Prospective register-based study of Norwegian regions. Int J Equity Health 2011;10:7.

22 Kawachi I, Subramanian SV, Almeida-Filho N. A glossary for health inequalities. J Epidemiol Community Health 2002;56:647-52.

23 Willson AE. 'Fundamental Causes' of health disparities: a comparative analysis of Canada and the United States. Int Sociology 2009;24:93-113.

24 Phelan JC, Link BG, Diez-Roux A, et al. 'Fundamental causes' of social inequalities in mortality: a test of the theory. J Health Soc Behav 2004;45:265-85.

25 Ross NA, Wolfson MC, Dunn JR. Relation between income inequality and mortality in Canada and in the United States: cross sectional assessment using census data and vital statistics. BMJ 2000;320:898-902.

26 Lundberg 0, Yngwe MA, Stjärne MK, et al. The role of welfare state principles and generosity in social policy programmes for public health: an international comparative study. Lancet 2008;372:1633-40.

27 Pickett KE, Wilkinson RG. Child wellbeing and income inequality in rich societies: ecological cross sectional study. BMJ 2007;335:1080.
28 Sengoelge $M$, Hasselberg M, Ormandy $D$, et al. Housing, income inequality and child injury mortality in Europe: a cross-sectional study. Child Care Health Dev Published Online Jan 302013.

29 Van Niekerk A, Rode H, Laflamme L. Incidence and patterns of childhood burn injuries in the Western Cape, South Africa. Burns 2004:30:341-7.

30 Morency P, Gauvin L, Plante C, et al. Neighborhood social inequalities in road traffic injuries: the influence of traffic volume and road design. Am J Public Health 2012:102:1112-19.

31 Braubach $\mathrm{M}$, Jacobs DE, Ormandy D, eds. Environmental burden of disease associated with inadequate housing: methods for quantifying health impacts of selected housing risks in the WHO European Region. Copenhagen: World Health Organization Regional Office for Europe, 2011.

32 Roys M, Davidson M, Nico S, et al. The real cost of poor housing. Watford (UK): Building Research Establishment Press, 2010.

33 Bergman $A B$, Rivara FP. Sweden's experience in reducing childhood injuries. Pediatrics 1991:88:69-74.

34 DiGuiseppi C, Jacobs DE, Phelan KJ, et al. Housing interventions and control of injury-related structural deficiencies: a review of the evidence. J Public Health Manag Pract 2010;16:\$34-43.

35 WHO Regional Office for Europe. Environmental health inequalities in Europe: assessment report. Copenhagen: World Health Organization Regional Office for Europe, 2012

36 Marsh A, Gordon D, Pantazis C, et al. Home sweet home? The impact of poor housing upon health. Bristol: The Policy Press, 1999.

37 Dedman DJ, Gunnell D, Smith G Davey, et al. Childhood housing conditions and later mortality in the Boyd Orr cohort. J Epidemiol Community Health 2001:55:10-15.

38 Eurostat. Comparative EU statistics on income and living conditions: issues and challenges. Luxembourg: European Communities, 2007.

39 European Defence Agency. European-United States defence expenditure in 2009. p. 3. 2010. http://www.eda.europa.eu/DefenceData (accessed 24 Jun 2011)

40 Bambra C, Gibson M, Sowden A, et al. Tackling the wider social determinants of health and health inequalities: evidence from systematic reviews. J Epidemiol Community Health 2010;64:284-91.

\section{Severe Traumatic Brain Injury in the USA}

A recent Morbidity and Mortality Weekly Report (MMWR) report summarises how public health efforts may reduce the incidence or reduce short- and long-term consequences of Traumatic Brain Injury. The solutions lie with primary prevention, early management, and comprehensive rehabilitation and community reintegration. In addition, the report urges improved surveillance, more evidence-based strategies, and the implementation of interventions that have been shown to work.

Editors note: The full report is commendable but curiously jumps from primary prevention to early management thus managing to avoid any mention of the role of helmets. http://www.cdc.gov/mmwr/preview/mmwrhtml/mm6227a2.htm?s_cid=mm6227a2_w. 